\title{
A Systematic Literature Review on Online Medical Services in Malaysia
}

\author{
https://doi.org/10.3991/ijoe.v16i06.13573 \\ Nohman Khan $(\varpi)$ \\ UniKL Business School Universiti Kuala Lumpur, Malaysia. \\ nohman.khanes.unikl.edu.my \\ Muhammad Imran Qureshi \\ Universiti Teknikal Malaysia Melaka, Melaka, Malaysia
}

\begin{abstract}
The aim of the study reviews online medical services in Malaysia. The paper reviews the improvement in Malaysian Medical services in the past five years. In this paper, we systematically reviewed literature from the year 2014 to 2018. We selected the web of science database for the literature search to make the process more transparent and clearer, every process is recorded on the excel sheets and all studies were screened through rigorous inclusion and exclusion criteria. Final 48 papers were selected for this systematic literature review and all irrelevant papers are excluded from the study. For the selection and exclusion process, PRISMA 2009 is used. The results revealed that Literature is heavily focusing on the medical services towards the urban areas, but rural areas were largely neglected. Many studies are discussing the importance of online medical services; However, implementation mechanisms have not been discussed. The systematic review recommends that future research should be focused more on holistic patterns of implementations of the online medical services in Malaysia.
\end{abstract}

Keywords - Online medical services, PRISMA, Systematic literature review

\section{Introduction}

The health care sector is one of the fast-growing and costly sector industries in the world and contributed a large part in the economies [1]. Normally public and private sector hospitals are providing healthcare services in many parts of the world. Public hospitals are more patient and pressure than the private sector hospitals, usually private hospitals are charging more charges and public hospitals are low charges but time consumption is a big issue due to large scale patients every day [2]. Private and government hospitals are facing huge unstable environment over the years due to climate changes and growing environmental issues, to deal with the new challenges in the medical health care sector is also transforming medical advance technology rapidly [3]. In Malaysia, $65 \%$ of patients are registered with public sector hospitals and generally in public sector hospitals are fees are low due to huge subsidy granted by the government [4]. The gov- 
ernment also works on infrastructural development of the health services sector in Malaysia and after every five minutes, a basic health unit is normally available to deal with the emergency situation [5]. On the other hand, private sector hospitals in the Malaysian medical services sector are also dealing with almost $25 \%$ of patients, they are usually not trusting on public hospital services are third party payments are giving them the opportunity to avail of the medical services from the private hospitals [6]. Malaysia's medical healthcare sector is declared first in the year 2019 due to services maturity and emergency response to patients, also looked up the management and infrastructural development in the healthcare sector is reason to provide quality healthcare services to citizens. While the public sector hospitals are still lacking in advance and standardized medical services, the problem starts from the influx of patient admission, unsatisfying surplus demand of population-healthcare services providers and perceptions of lowquality services [7]. Additionally, patients are tolerating long waiting times, service orientation of doctors, emotional stress, lack of doctors' professionalism and looking more for monetary gains than the services to human being [8]. This make very difficult for the population to avail services provide by the public sector hospitals. To deal with the problems related to medical services Malaysian government also adopt the idea of private and public sector partnership for development and improvement in the medical services sector [9]. Public and private partnership (PPPs) are not only limited to the health sector but also in other sector applied for the betterment and advancement in the managerial style.

In the medical sector, the idea was to nourish the public sector hospitals with flow sharing with the private hospitals and improvement in the strength of public sector medical service. In this study, during the year 2014 to 2018, we will find the direction and areas where research is focused on. Medical services are also changing in the world very rapidly and advancement not only in equipment but also in practices is growing. This study will overview the medical services in Malaysia, which areas are pointed out and where is needed future research for the development of the batter medical services. The aim of the study is to make an overview of medical services available in Malaysia and how the government is working to improve the service with time. Medical advancement and technology growth in this century is one of the best revolutions for human civilization, to ensure health care is one of the basic responsibilities of every society. Digitalization makes easier to find the services quality and human error is very much limited due to the involvement of technology. The study has selected the web of science database for the results collection, to make the process more transparent and clearer, every process is recorded on the excel sheets and all options are used very carefully for batter results.

\section{Methodology}

The study analysis the past literature to a systematic literature review (SLR). The PRISMA statement templet is used to explain the overall process of selection and rejections of Article for the review of medical services in Malaysia. The PRISMA statement helps the researcher to improve the reporting of the review paper. The review is 
limited to published literature. The PRISMA 2009 is showing the complete process in the figure 1 .

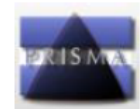

PRISMA 2009 Flow Diagram

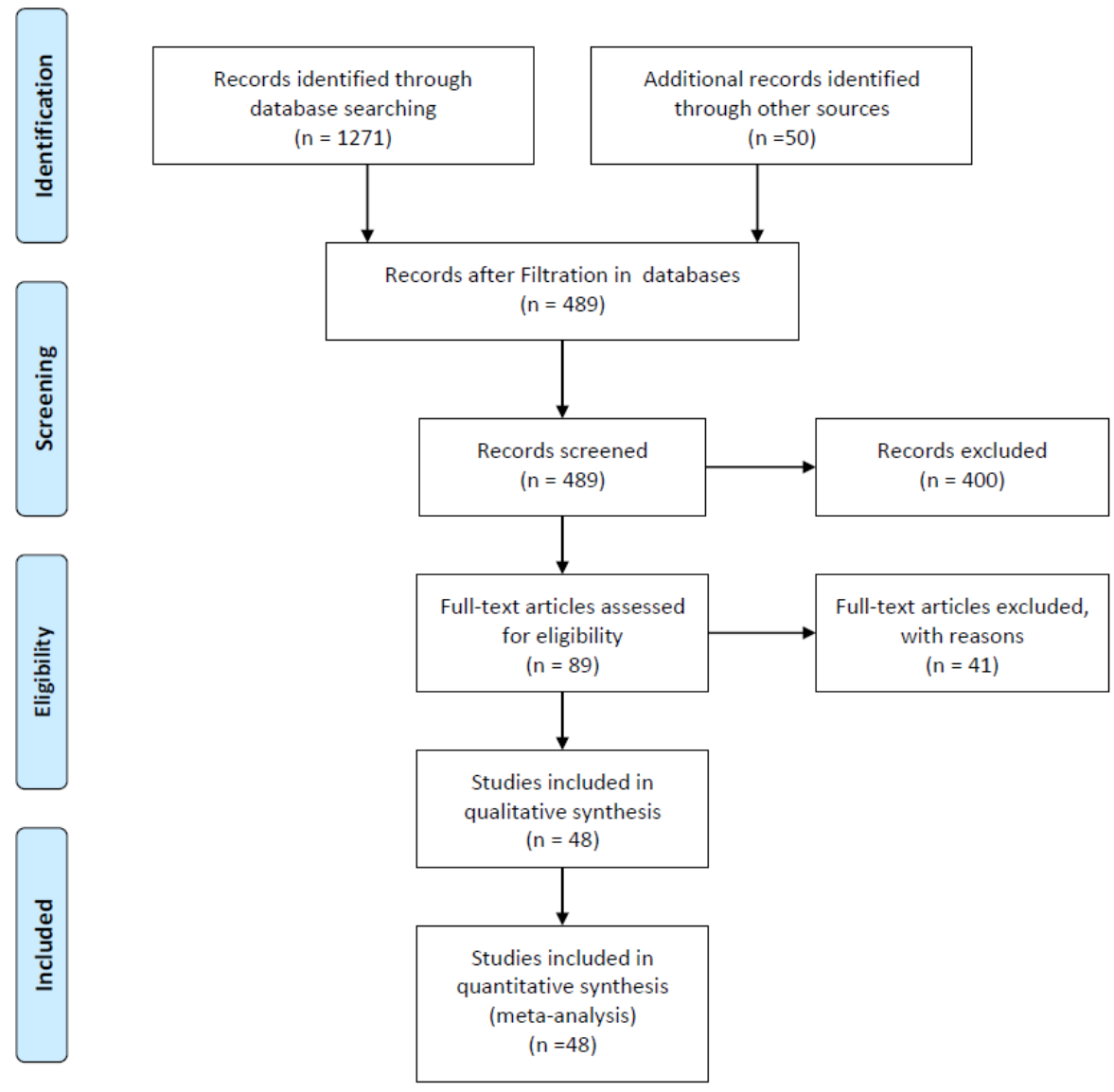

Fig. 1. PRISMA 2009 diagram

\subsection{Quality assessment}

The review papers are based only on articles and review papers and conference papers are excluded from the study. for maintaining the quality of the review, every kind of duplication is checked very thoroughly on the excel sheet. Abstracts and conclusions of the articles are checked deeply for the analysis and purification of the articles to make sure at the possible level. 


\subsection{Studies included in qualitative synthesis}

The final 48 studies are used for the final process and find the direction and research done by the researcher in the year 2014 to 2018. the subject wise research is also explained in the graph to show the number of papers is include and exclude for the review.

\subsection{Year base publications}

The year-wise publications according to the most cited papers are shown in the diagram. The year 2014 is the initial year selected for the review and the highest number is selected from the year 2018. The year-wise publications record is shown in figure 2 and total papers are selected from the year 2018 is 14 and it is the highest number and the lowest number is from the year 2014. The year 2017 is second highest paper selection with 11 papers.

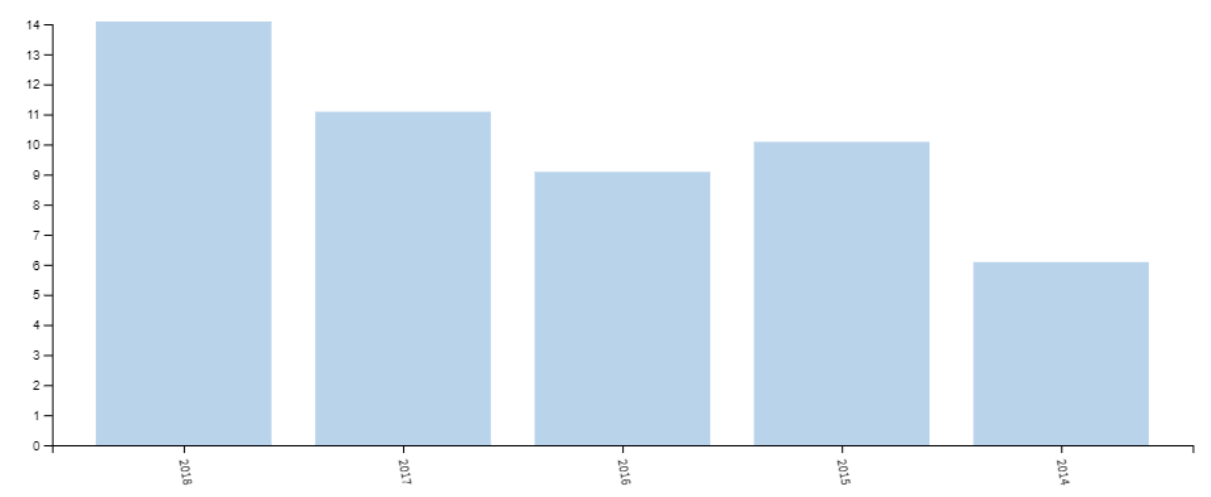

Fig. 2. Year wise publications

\subsection{Journal base publications}

The other important assessment that is made for the study is Journal area identification in the study. most of the papers are selected from the medicine general international with 21 papers. Health care sciences and health policy services are also categorically contributed to the study. The results are shown in figure 3 below. 


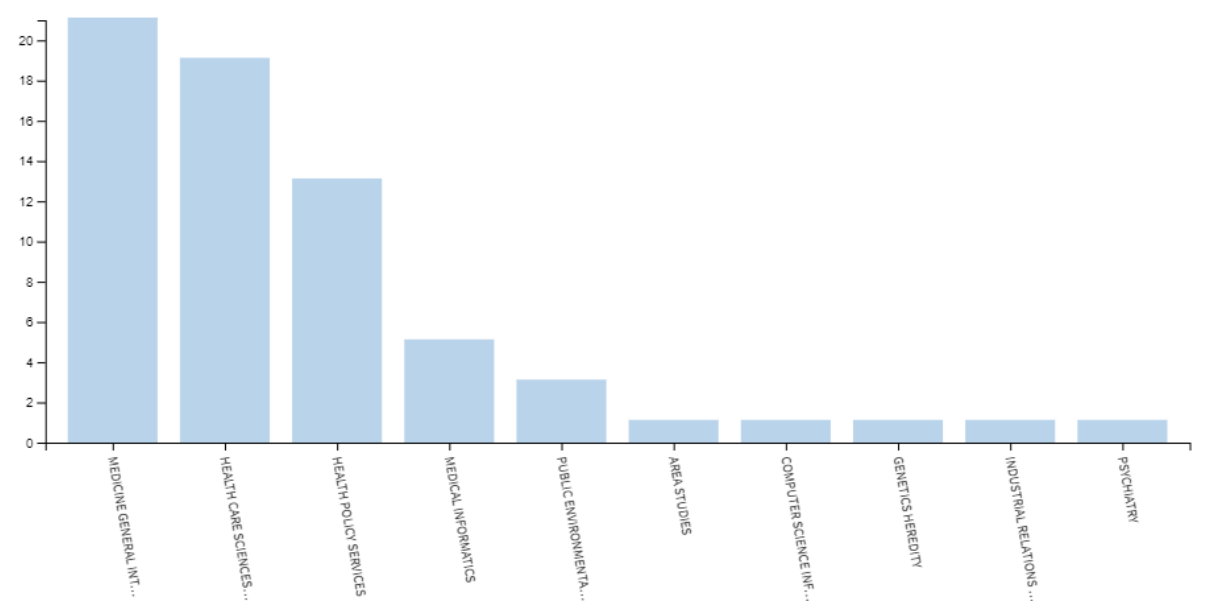

Fig. 3. Journal Based Publication

\section{Classification of Literature}

\subsection{Healthcare services}

In the data processing from the database web of science healthcare services are discussed 9 studies by the researchers, one of study is suggested that medical education needs to advancement due to rapid development in the medical field. Health care professionals upgrade knowledge for improvement in healthcare [10]. According to [11] patient satisfaction in healthcare is a dynamic concept, that connects with important dimensions such as technical, functional, infrastructure, interaction, and atmosphere. Patient trust is positively influenced by the patient satisfaction that generally promotes the hospital value and market share [12]. Table 1 is showing the classification and findings of the literature selected for the study. Another study also talks about the healthcare services for a competitive advantage, the author suggested that hospitals should focus on achieving customer satisfaction and loyalty by delivering premium services [13].

One study also talks about the men's health in Malaysia, the study argues that men's health occurs due to a lack of awareness of men's health issues and men also ignore the importance of health screening. Literature concluded with the point that men's health needs a batter understanding and develops behavior to remove the barriers to men's health [14]. 
Table 1. Table of Classifications.

\begin{tabular}{|l|l|}
\hline \multicolumn{1}{|c|}{ Variables } & \multicolumn{1}{c|}{ Findings } \\
\hline Healthcare Services & $\begin{array}{l}\text { The Community Health Care Van (CHCV) is a mobile medical clinic (MMC) } \\
\text { that has served vulnerable populations in New Haven }\end{array}$ \\
\hline $\begin{array}{l}\text { The emergency of Medical } \\
\text { Services }\end{array}$ & $\begin{array}{l}\text { population coverage of hypertension treatment services can be used to make } \\
\text { inferences about the performance of primary care services within health sys- } \\
\text { tems. }\end{array}$ \\
\hline Cancer Disease & $\begin{array}{l}\text { Training is needed to avoid missed diagnoses and other factors contributing to } \\
\text { delay among health professionals. }\end{array}$ \\
\hline HIV Prevention Strategies & $\begin{array}{l}\text { Ethnicity and sexual orientation of Malaysian patients may play a significant } \\
\text { role in their level of adherence to scheduled clinic appointments. }\end{array}$ \\
\hline Telecare/ social media & $\begin{array}{l}\text { Social media may be an effective educational medium for improving } \\
\text { knowledge of health professionals, fostering their use of research evidence, } \\
\text { and changing their clinical behaviors by translating new research evidence } \\
\text { into clinical practice. }\end{array}$ \\
\hline Dengue infection & $\begin{array}{l}\text { The diagnostic performance of the ICD codes for dengue in the MOH's hospi- } \\
\text { tal discharge database is adequate for use in health services research on den- } \\
\text { gue. }\end{array}$ \\
\hline Foreigner/ tourist care & $\begin{array}{l}\text { This has implications on policy and health care provision and access for for- } \\
\text { eigners and future studies are needed to look into strategies to solve these } \\
\text { problems. }\end{array}$ \\
\hline
\end{tabular}

\subsection{The emergency of medical services}

Emergency medical services are very difficult and dedicated services that are done inside and outside the hospital usually. The vital services are response duration and preparedness of medical services. In modern times applications like space and geospatial technology such as satellite navigation systems and Geographical information systems are needed to update for the emergency operations[15]. Emergency medical services are a very sensitive and complicated kind of problem from the common man point of view and they are very determined to know the quality of services provide by the hospitals [16]. Literature also suggested that a small mistake will lead to serious and life-threatening impressions for the consumer and the negative impact of the medical services will attach, so the delegated quality standards are important to meet in the medical profession [17]. Hajli, Shanmugam, Hajli, Khani, \& Wang, (2015) suggested that the empower web2.0 can create content and share with the patients online in a short time for emergency situations and penetration of social media is making this more reliable. The population is joining and health professionals are contacting each other through online platforms for better handling of emergency situations. Social media is also one of very relevant forums to handle emergency events for medical assistance point of view.

\subsection{Cancer disease \& HIV prevention strategies}

Literature from the year 2014 to 2018 also explores the very hot and sensitive diseases like HIV positive and cancer patients. Abdulrahman et al., [18] study highlighted the sociodemographic profile and predictors of outpatient visits of Malaysian antiretroviral therapy patients. The main idea is conveying and delivers mobile messages and 
reminders about the important dates and timing for therapy attendance. To engage peers and patients towards the therapy among HIV positive patients in Malaysia. HIV positive patients need strict medication adherence and regular clinic appointments schedule. Like the other chronic diseases, continuous visits to the clinic, medication refill, laboratory tests and clinic treatments are prior to achieving the success and good clinical results [18]. Researchers are focusing to conceptualize the efficient assistance to HIV positive patients. Another important area discussed about Breast cancer and Cervical cancer. Malaysian women are a high rate in breast cancer and adopt a unique strategy for screening, women's having a high risk of breast cancer in Malaysia due to symptoms or family factors history offered mammography screening. Annually women are called for screening in clinics. Screening annual basis provided records and wellness and any changes in a women's body that is a threat for breast cancer and also government outpatient clinics [19]. Breast cancer is the number one reported cancer in Malaysia and a second high number is a Cervical cancer in women. Literature also contributed to Cervical cancer in the database. The findings of the study, both medical and paramedical staff should be learning about HPV vaccination at a mandatory level. The study also concluded that knowledge and attitude level toward cervical cancer is correlated, as it is knowledge about the disease is high in doctors rather than nurses. The study also recommended that for improving the lifestyle and health safety among the women, the Malaysian government focuses to adopt the screening more advance and scientific techniques [20].

\subsection{Dengue infection}

In literature shows the record that the dengue fatality ratio is a bit low compared to other countries, 2.4 deaths are recorded over 100000 notified cases. The majority of disease-infected patients are asymptomatic and suffer low health consequences and prevalence are measure the frequency of disease rather than measure the disease burden [21]. The study in the review suggested the dengue infection that for developing and conducting research about the dengue virus in Malaysia, the government must provide data of infected dengue patients to researchers for future recommendations and batter planning medication to control virus [22]. About dengue disease, principle complication is vascular permeability, that is decrease with age. Signs of plasma leakage and decrease in platelet are more prevalent in infants, followed by children and adults and related to positive dengue diagnose in the laboratory [22].

\subsection{Telecare and social media}

The health sector is significantly changing due to rapid changes in information technology advancement over the years. Technological advancement creates a positive impact on the health care efficiency, safety and quality and leads to deliver batter services in medical services [23]. Literature in the current study imported from the web of science database, continuous recommendations and conclusion about the adoption of telecommunication advancement in the health care sector in Malaysia. Social media pen- 
etration in every sector is also phenomenal and the health sector also working to improve the response of patients for batter health services in Malaysia. Many authors in the study contributed to social media platforms are available to handle emergency conditions. Doctors and patients are widely using social media for approaching each other and make appointments through the networks [24]. [25] Social media is coming to an effective mode of education for providing information to clinics for improving the knowledge, health professionals are using research evidence towards health issues and changing the behaviors after adopting new research techniques in clinical practices. Historical hierarchies are also changed by social media through information sharing and the quality of information. It usually sharing direct information and provides an opportunity to clinicians, health researchers, professional associations, authors of journal articles and other figures of industries. Researcher and clinicians are directly in connection with each other and social media provide tailored and direct connection for knowledge and practice, overcoming the many obstacles for the research area. This is also reducing and overcoming the evidence to practice gap[26].

\subsection{Foreigner/ Tourist care}

Researchers and policymakers both are taken medical tourism to be a surprise, never be vibrant before as today it is. International tourist can rush towards medical health center in Malaysia, now the health cares have often been as local for the health sector [27]. A study finding in the research as an integrated model according to the consumer point of view toward solid medical tourism. Medical context is according to the theories on medical tourism accordingly brand name creates an image to influence the foreigner patients[13]. Medical tourists worldwide growing rapidly and Malaysian tourism medical health care sector are creating a great business opportunity for the health care sector and tourism industry [27]. The researcher is believing that medical tourism is creating more values for the medical and tourism industry after creating a smooth medical service for the international tourist.

\section{Conclusion}

After processing 48 research papers from the web of science database, we cannot avoid the evidence and the majority of Articles are dominant in medical services through long term management. However, medical services are still needed to improve in many dimensions. Literature is heavily focusing on the medical services towards the urban's areas, but rural areas research is still missing in the literature. Many studies are discussing the importance of medical services and implementation and development are still has a gap to discuss. Researchers can explore serious disease services in Malaysia. The study finds that medical emergency and services are widely highlighted but some serious medical emergency matters are missing very much in published literature. One of the more significant findings to emerge from this study is that online medical services literature is very limited in Malaysia and future researchers must come through the area. 


\section{$5 \quad$ References}

[1] M. C. Kocakülâh and A. D. Austill, "Balanced scorecard application in the health care industry: A case study," J. Health Care Finance, vol. 34, no. 1, pp. 72-99, 2007.

[2] A. W. Ghazali, N. A. Shafie, and Z. M. Sanusi, "Earnings Management: An Analysis of Opportunistic Behaviour, Monitoring Mechanism and Financial Distress," Procedia Econ. Fi-nanc., vol. 28, pp. 190-201, 2015. https://doi.org/10.1016/S2212-5671(15)01100-4

[3] J. S. Krupa et al., "Analysis of a consumer survey on plug-in hybrid electric vehicles," Transp. Res. Part A Policy Pract., vol. 64, pp. 14-31, Jun. 2014. https://doi.org/10.1 016/j.tra.2014.02.019

[4] "Portal rasmi Kementerian Kesihatan Malaysia," Kementerian Kesihatan Malaysia, 2019.

[5] "Quek et al. - Unknown - The Malaysian Health Care System A Review."

[6] N. Rajah Rasiah, "Markets and Healthcare Services in Malaysia: Critical Issues," Institutions Econ., vol. Volume 3, no. Issue 3, 2012.

[7] K. Ganasegeran and S. A. R. Al-Dubai, "Medical professionalism from a socio-cultural perspective: Evaluating medical residents communicative attitudes during the medical encounter in Malaysia," J. Postgrad. Med., vol. 60, no. 1, pp. 12-15, 2014. https://doi.org/10.4103 10022-3859.128799

[8] K. Ganasegeran, W. Perianayagam, R. Abdul Manaf, S. A. Ali Jadoo, and S. A. R. Al-Dubai, "Patient satisfaction in Malaysia's busiest outpatient medical care," Sci. World J., vol. 2015, pp. 1-6, 2015. https://doi.org/10.1155/2015/714754

[9] K. L. Phua, S. W. H. Ling, and K. H. Phua, "Public-Private Partnerships in Health in Malaysia: Lessons for Policy Implementation," Int. J. Public Adm., vol. 37, no. 8, pp. 506-513, Jul. 2014. https://doi.org/10.1080/01900692.2013.865647

[10] C. E. Tan, A. Jaffar, N. Tohit, Z. Hamzah, and S. M. Hashim, "Exploring patients' reasons for participation in a medical education home visit program: a qualitative study in Malaysia," Per-spect. Med. Educ., vol. 6, no. 3, pp. 182-188, Jun. 2017. https://doi.org/10.1007/s40037017-0353-1

[11] C. W. Ng, M. R. Shahari, J. Mariapun, N. N. M. Hairi, S. Rampal, and A. Mahal, "Universal coverage of hypertension treatment services in Malaysia is still an elusive goal," Heal. Syst. Re-form, vol. 3, no. 3, pp. 159-170, Jul. 2017. https://doi.org/10.1080/ 23288604.2017 .1342746

[12] A. Kohno, G. Musa, N. D. Nik Farid, N. Abdul Aziz, T. Nakayama, and M. Dahlui, "Issues in healthcare services in Malaysia as experienced by Japanese retirees," BMC Health Serv. Res., vol. 16, no. 1, p. 167, Dec. 2016. https://doi.org/10.1186/s12913-016-1417-3

[13] T. H. Cham, Y. M. Lim, N. C. Aik, and A. G. M. Tay, "Antecedents of hospital brand image and the relationships with medical tourist' behavioral intention," Int. J. Pharm. Healthc. Mark., vol. 10, no. 4, pp. 412-431, Nov. 2016. https://doi.org/10.1108/IJPHM-02-2016-0012

[14] S. Ahmad Arifin, A. Mat Yusuf, R. Ili Nabilah, L. Md Isa, M. Kuantan, and M. Lokman Md Isa, "IMJM Volume 17 Special Issue No 2 2nd World Congress on Integration and Islamicisation Health Seeking Behavior of Health Disorders of Men among Government Servants in Kuantan: Prevalence Study towards a Healthy Ummah."

[15] W. H. Ooi, I. M. Shahrizal, A. Noordin, M. I. Nurulain, and M. Y. Norhan, "Development of Rural Emergency Medical System (REMS) with geospatial technology in Malaysia," in IOP Conference Series: Earth and Environmental Science, 2014, vol. 18, no. 1, p. 012130. https://doi.org/10.1088/1755-1315/18/1/012130

[16] M. Altaf, N. Tabassum, and S. S. M. Mokhtar, "Brand equity and the role of emergency medical care service quality of private cardiac institutes: An empirical investigation," Int. J. 
Pharm. Healthc. Mark., vol. 12, no. 1, pp. 44-60, Apr. 2018. https://doi.org/10.1108/IJPHM09-2016-0046

[17] M. N. Hajli, M. Shanmugam, A. Hajli, A. H. Khani, and Y. Wang, "Health care development: Integrating transaction cost theory with social support theory," Informatics Heal. Soc. Care, vol. 40, no. 4, pp. 334-344, Oct. 2015. https://doi.org/10.3109/17538157.2014.924950

[18] S. A. Abdulrahman, L. Rampal, N. Othman, F. Ibrahim, K. S. Hayati, and A. P. Radhakrishnan, "Sociodemographic profile and predictors of outpatient clinic attendance among HIVpositive patients initiating antiretroviral therapy in Selangor, Malaysia," Patient Prefer. Adherence, vol. 11, pp. 1273-1284, 2017. https://doi.org/10.2147/PPA.S141609

[19] J. N. W. Lim et al., "Barriers to early presentation of self-discovered breast cancer in Singapore and Malaysia: A qualitative multicentre study," BMJ Open, vol. 5, no. 12, 2015. https://doi.org/10.1136/bmjopen-2015-009863

[20] S. A. Sheikh, M. Haque, S. Ismail, U. Y. Hussein, and N. Bin Simbak, "Knowledge and attitudes toward HPV vaccination among healthcare givers: First multicentre survey in Malaysia," Austral-as. Med. J., vol. 10, no. 4, pp. 361-372, 2017. https://doi.org/10.2 1767/AMJ.2017.2954

[21] S. S. Sam, S. F. S. Omar, B. T. Teoh, J. Abd-Jamil, and S. AbuBakar, "Review of Dengue Hemorrhagic Fever Fatal Cases Seen Among Adults: A Retrospective Study," PLoS Neglected Tropical Diseases, vol. 7, no. 5. Public Library of Science, p. e2194, May-2013. https://doi.org/10.1371/journal.pntd.0002194

[22] Y. L. Woon, K. Y. Lee, S. F. Z. Mohd Anuar, P. P. Goh, and T. O. Lim, "Validity of International Classification of Diseases (ICD) coding for dengue infections in hospital discharge records in Malaysia," BMC Health Serv. Res., vol. 18, no. 1, p. 292, Dec. 2018. https://doi.org/10.1186/s12913-018-3104-z

[23] K. A. Ratnam, P. D. D. Dominic, and T. Ramayah, "A structural equation modeling approach for the adoption of cloud computing to enhance the Malaysian healthcare sector systemslevel quality improvement," J. Med. Syst., vol. 38, no. 8, p. 82, Aug. 2014. https://doi.org/10.1007/s10916-014-0082-5

[24] S. Maloney et al., "Translating evidence into practice via social media: A mixed-methods study," J. Med. Internet Res., vol. 17, no. 10, 2015. https://doi.org/10.2196/jmir.4763

[25] Z. Siddiqui, A. H. Abdullah, M. K. Khan, and A. S. Alghamdi, "Smart environment as a service: Three factor cloud based user authentication for telecare medical information system," J. Med. Syst., vol. 38, no. 1, p. 9997, Jan. 2014. https://doi.org/10.1007/s10916-0139997-5

[26] F. Behrouzi, A. M. Shaharoun, and A. Ma'Aram, "Applications of the balanced scorecard for strategic management and performance measurement in the health sector," Aust. Heal. Rev., vol. 38, no. 2, pp. 208-217, 2014. https://doi.org/10.1071/AH13170

[27] N. H. Abd Manaf, H. Hussin, P. N. Jahn Kassim, R. Alavi, and Z. Dahari, "Country perspective on medical tourism: The malaysian experience," Leadersh. Heal. Serv., vol. 28, no. 1, pp. 43-56, Feb. 2015. https://doi.org/10.1108/LHS-11-2013-0038

[28] T. R. Q. M. I. Shafiq M., "A developed framework of mediating role of inbound innovation strategy between bos and innovation performance," Int. J. Eng. Adv. Technol., vol. 8, no. 5, pp. 1375-1381, 2019. https://doi.org/10.35940/ijeat.E1196.0585C19

[29] M. I. Qureshi, S. Qayyum, A. A. Nassani, A. M. Aldakhil, M. M. Q. Abro, and K. Zaman, "Management of various socio-economic factors under the United Nations sustainable develop-ment agenda," Resour. Policy, vol. 64, p. 101515, 2019. https://doi.org/10.1016/j.re$\underline{\text { sourpol.2019.101515 }}$ 
[30] M. I. Qureshi et al., "Measuring the ecological footprint of inbound and outbound tourists: evidence from a panel of 35 countries," Clean Technol. Environ. Policy, 2019. https://doi.org/10.1007/s10098-019-01720-1

[31] M. I. Qureshi, R. M. Yusoff, S. S. Hishan, A. F. Alam, K. Zaman, and A. M. Rasli, "Natural disasters and Malaysian economic growth: policy reforms for disasters management," Environ. Sci. Pollut. Res., vol. 26, no. 15, pp. 15496-15509, May 2019. https://doi.org/10.1007 /s11356-019-04866-z

[32] M. I. Qureshi et al., "Modeling Work Practices under Socio-Technical Systems for Sustainable Manufacturing Performance," Sustainability, vol. 11, no. 16, p. 4294, Aug. 2019. https://doi.org/10.3390/su11164294

[33] M. Shahverdi, K. Ismail, and M. I. Qureshi, "The effect of perceived barriers on social entrepreneurship intention in Malaysian universities: The moderating role of education," Manag. Sci. Lett., vol. 8, no. 5, pp. 341-352, 2018. https://doi.org/10.5267/j.msl.2018.4.014

[34] A. M. Rasli, M. I. Qureshi, A. Isah-Chikaji, K. Zaman, and M. Ahmad, "New toxics, race to the bottom and revised environmental Kuznets curve: The case of local and global pollutants," Re-newable and Sustainable Energy Reviews, vol. 81. pp. 3120-3130, 2018. https://doi.org/10.1016/j.rser.2017.08.092

[35] M. I. Qureshi, R. M. Yusoff, A. R. Ahmed, K. Isa, and A. Imran, "Linking quality of work life with sustainable manufacturing performance," Adv. Sci. Lett., vol. 23, no. 9, pp. 82328235, 2017. https://doi.org/10.1166/asl.2017.9867

[36] M. I. Qureshi, M. A. Hassan, S. S. Hishan, A. M. Rasli, and K. Zaman, "Dynamic linkages between sustainable tourism, energy, health and wealth: Evidence from top 80 international tourist destination cities in 37 countries," J. Clean. Prod., vol. 158, pp. 143-155, 2017. https://doi.org/10.1016/j.jclepro.2017.05.001

[37] M. Rashid, R. Tasmin, M. Qureshi, and M. Shafiq, "Relationship of servant leadership with employee in-role and extra-role performance in GLC's of Malaysia," City Univ. Res. J., no. 2010, pp. 88-95, 2017.

[38] M. I. Qureshi, U. Awan, Z. Arshad, A. M. Rasli, K. Zaman, and F. Khan, "Dynamic linkages among energy consumption, air pollution, greenhouse gas emissions and agricultural production in Pakistan: sustainable agriculture key to policy success," Nat. Hazards, vol. 84, no. 1, pp. 367-381, 2016. https://doi.org/10.1007/s11069-016-2423-9

[39] R. B. M. Yusoff, A. Imran, M. I. Qureshi, and A. G. Kazi, "Investigating the relationship of employee empowerment and sustainable manufacturing performance," Int. Rev. Manag. Mark., vol. 6, no. 4, pp. 284-290, 2016.

[40] M. I. Qureshi, N. U. Khan, A. M. Rasli, and K. Zaman, "The battle of health with environmental evils of Asian countries: promises to keep," Environ. Sci. Pollut. Res., vol. 22, no. 15, pp. 11708-11715, 2015. https://doi.org/10.1007/s11356-015-4440-8

[41] M. I. Qureshi et al., "Environment and air pollution: health services bequeath to grotesque menace," Environ. Sci. Pollut. Res., vol. 22, no. 5, pp. 3467-3476, 2015. https://doi.org/10.1007/s11356-014-3584-2

[42] M. I. Qureshi, A. Md. Rasli, A. Jusoh, and T. O. Kowang, "Sustainability: A new manufacturing paradigm," J. Teknol., vol. 77, no. 22, pp. 47-53, 2015. https://doi.org/10.1 $\underline{1113 / \text { jt.v77.6661 }}$

[43] M. I. Qureshi, A. Khan, K. Zaman, and N. Khaqan, "Structural investigation of service quality in conventional and islamic banking in pakistan," Int. J. Manag. Innov., vol. 6, no. 1, p. 84, 2014.

[44] I. Q. Muhammad, B. Mansoor, K. Aamir, and Z. Khalid, "Measuring queuing system and time standards: A case study of student affairs in universities," African J. Bus. Manag., vol. 8, no. 2, pp. 80-88, 2014. https://doi.org/10.5897/AJBM2013.7247x 
[45] M. I. Qureshi, S. Y. Janjua, K. Zaman, M. S. Lodhi, and Y. Bin Tariq, "Internationalization of higher education institutions: Implementation of DMAIC cycle," Scientometrics, vol. 98, no. 3, pp. 2295-2310, 2014. https://doi.org/10.1007/s11192-013-1163-9

[46] M. I. Qureshi, A. M. Rasli, and K. Zaman, "A New Trilogy to Understand the Relationship among Organizational Climate, Workplace Bullying and Employee Health," Arab Econ. Bus. J., vol. 9, no. 2, pp. 133-146, 2014. https://doi.org/10.1016/j.aebj.2014.05.009

[47] M. I. Qureshi, M. N. Bhatti, A. M. Rasli, M. Yasir, and K. Zaman, "The Delphi method for internationalization of higher education in Pakistan: Integrating theory of constraints and quality function deployment," Mediterr. J. Soc. Sci., vol. 5, no. 20, pp. 2702-2710, 2014. https://doi.org/10.5901/mjss.2014.v5n20p2702

[48] M. I. Qureshi, A. Rustum, S. Rustum, A. Bin Omar, and K. Zaman, "Factors influencing customer satisfaction in banking sector of Pakistan," Rep. Opin., vol. 5, no. 2, pp. 35-39, 2013.

[49] M. I. Qureshi, M. Iftikhar, M. N. Bhatti, T. Shams, and K. Zaman, "Critical elements in implementations of just-in-time management: Empirical study of cement industry in Pakistan," Springerplus, vol. 2, no. 1, pp. 1-14, 2013. https://doi.org/10.1186/2193-1801-2-645

[50] M. I. Qureshi, M. Iftikhar, S. G. Abbas, U. Hassan, K. Khan, and K. Zaman, "Relationship between job stress, workload, environment and employees turnover intentions: What we know, what should we know," World Appl. Sci. J., vol. 23, no. 6, pp. 764-770, 2013.

[51] M. I. Qureshi, A. Rustam, S. Rustam, A. Bin Umar, and K. Zaman, "Measuring Bank Branch Performance in Pakistan: Data Envelopment Analysis (DEA)," Oeconomics Knowl., vol. 4, no. 4, pp. 25-40, 2012.

[52] M. I. Qureshi, A. Khan, and K. Zaman, "Structural Investigation of Service Quality in Conventional and Islamic Banking in Pakistan," Int. Rev. Manag. Mark., vol. 2, no. 2, pp. 99$105,2012$.

[53] M. I. Qureshi, "Customer Satisfaction Measurement and Analysis Using Six Sigma in Telecom Sector of Pakistan," Eur. J. Sustain. Dev., vol. 1, no. 1, pp. 53-68, 2012.

[54] M. I. Qureshi, K. Khan, M. N. Bhatti, A. Khan, and K. Zaman, "Quality function deployment in higher education institutes of Pakistan," Middle East J. Sci. Res., vol. 12, no. 8, pp. 11111118, 2012.

\section{Authors}

Nohman Khan is from UniKL Business School Universiti Kuala Lumpur, Malaysia. The research area of author is digital marketing and ecotourism. Author is having media background and worked with Tv channels. For contact email: nohman.khan@s.unikl.edu.my

Muhammad Imran Qureshi is currently affiliated with Faculty of Technology Management and Technopreneurship, Universiti Teknikal Malaysia Melaka, Malaysia. Author completed his PhD from Universiti Teknologi Malaysia (UTM) in year 2016. The area of interest of Dr. Muhmmad Imran Qureshi is operations management and open innovation. Author is writer of three books and more than 120 research publications.

Article submitted 2020-02-04. Resubmitted 2020-03-27. Final acceptance 2020-03-30. Final version published as submitted by the authors. 